\title{
Wound Complications in Obese Patients after Gynecologic Oncology Surgeries, an Intervention Study
}

Hussein Mohammed Abdeldaim, Taha Abdelfattah Ahmed, Esraa Gomaa Mustafa Alsyied*, Mohammed Mustafa Zaitoun

Department of Obstetrics and Gynecology, Faculty of Medicine, Zagazig University, Egypt

*Correspondence to: Esraa Gomaa Mustafa Alsyied, Mobile: (+20)1068973935, E-mail: Gomaae975@ gmail.com

\begin{abstract}
Background: Obesity is one of the comorbid conditions which can affect the operative and postoperative outcome of patients undergoing surgery.

Objective: The aim of the current work was to assess the impact of using specific protocol suggested by author included (saline wash, suture material, subcutaneous drain and binder) on wound complications after major gynecologic Oncology surgeries in obese patients.

Patients and Methods: This study was an intervention prospective study which included 86 women undergoing surgical gynecologic procedures via a vertical abdominal incision performed at Obstetrics and Gynecology Department, Faculty of Medicine, Zagazig University Hospital during the period from April 2020 to October 2020. All patients were subjected to detailed history taking, Clinical examination including general, abdominal and pelvic examination. Surgical Protocol for skin closure was applied.

Results: There was a significant difference between study group and control group regarding wound complications $(\mathrm{P}=0.001)$. Fever was found in $23.2 \%$ in study group and $34.8 \%$ in control group, seroma was found in $100 \%$ in study group and $80 \%$ in control group and wound dehiscence, wound infection and wound hematoma respectively were found in $100 \%$ in study group and $60 \%$ in control group.

Conclusion: It could be concluded that using this specific protocol (saline wash, suture material (Polydioxanone Suture), subcutaneous drain and binder) may decrease the incidence of wound complications in obese women undergoing a gynecologic procedure via a vertical abdominal incision.

Keywords: Wound Complications, Obese Patients, Oncology Surgeries, saline wash
\end{abstract}

\section{INTRODUCTION}

Obesity is comorbid conditions which can affect the operative and postoperative outcome of patients undergoing surgery ${ }^{(\mathbf{1})}$.

It is better expressed by body mass index (BMI). BMI is calculated from weight and height. Body mass index of less than 18.5 is underweight, 18.5 to 24.9 is normal, 25 to 29.9 is overweight and more than 30 is obesity ${ }^{(2)}$.

The distribution of body fat between visceral and non-visceral compartments and within different subcutaneous areas is important clinically. Both the central and peripheral types of obesity are associated with surgical complications ${ }^{(3,4)}$.

The Gynecologic Oncology surgeries may be open or laparoscopic and elective or emergency. Possible complications of these surgeries may be local or systemic $^{(5)}$.

The local complications include hemorrhage, infection, damage to internal organs, formation of adhesions, bowel obstruction, seroma, wound dehiscence, hernia ${ }^{(6)}$.

The systemic complications are like chest infection, septicemia, deep venous thrombosis, nosocomial infections, ischemic heart disease and some procedure related complication ${ }^{(7)}$.

Infectious complications of these surgeries range from skin and soft tissue infection to intra-abdominal abscess and peritonitis. The etiology may be related to type of surgery, diabetes mellitus, (DM) poor technique, obesity, or disorders of immune system. ${ }^{(8)}$.

Seroma can be due to subcutaneous potential space or inadequate drainage. This may lead to wound infection ${ }^{(9)}$.

Wound dehiscence, in particular, leads to incisional hernia. Risk factors for the development of wound dehiscence and hernia include chronic pulmonary disease, ascites, jaundice, anemia, obesity, coughing, type of surgery, wound infection and closure technique. Incisional hernias can occur after any type of abdominal wall incision, but midline incisions are more prone to have this complication ${ }^{(\mathbf{1 0})}$.

Perioperative risk factors are age, hypertension, diabetes mellitus, heart diseases, renal failure, cirrhosis, pulmonary disease, endocrine disorders, smoking, obesity, and coagulopathy. These disorders need to be controlled before the surgery ${ }^{(11)}$.

The operative problems associated with obesity are difficulty in exposure and closure, bleeding, prolonged operative time, visceral damage, wound infection, dehiscence, incisional hernia ${ }^{(12)}$.

The aim of this study was to assess the impact of using specific protocol (suggested by author) as (saline wash, suture material, subcutaneous drain and binder) on wound complications after major gynecologic Oncology surgeries in obese patients. 


\section{PATIENTS AND METHODS:}

This intervention prospective study included a total of 86 women undergoing surgical gynecologic procedures via a vertical abdominal incision, attending at in Obstetrics and Gynecology Department, Faculty of Medicine, Zagazig University Hospitals. This study was conducted between April 2020 to October 2020.

The included subjects were divided into two groups; Group 1 (study group) consisted of 43 women undergoing gynecologic procedures via a vertical abdominal incision using the suggested protocol and Group 2 (control group) consisted of 43 women undergoing gynecologic procedures via a vertical abdominal incision without-using the suggested protocol.

\section{Ethical Consideration:}

Written informed consent was obtained from each subject before participation and the study was approved by the Hospital Ethics Committee of Zagazig University. The Ethics Committee of the Institute approval the study and performed as per the ethical standards laid down in 1964 (Declaration of Helsinki and its later amendments.

\section{Inclusion criteria:}

Women between the age 18-65 years, with a BMI $\geq 30 \mathrm{~kg} / \mathrm{m}^{2}$ at the time of admission class 1 from 30-34.9 with low risk, class 2 from 35-39.9with moderate risk class $3 \geq 40$ with high risk, diagnosed gynecologic malignant tumor, the patients were prepared for surgery via a vertical abdominal incision.

\section{Exclusion criteria:}

Planned laparoscopic surgery, planned panniculectomy or other plastic surgery procedure at the time of laparotomy, prior history of hernia repair with mesh or planned mesh hernia repair at the current procedure, enterotomy or intestinal surgery, a history of prior radiation to the abdomen or pelvis, concurrent pregnancy, inability to provide informed consent.

A comprehensive history was taken from each participant. Clinical examination had been done including general, abdominal and pelvic examination. General examination included general appearance, weight, height, body mass index and vital signs (pulse, blood pressure and temperature). Abdominal examination to detect ascites, abdominal mass, and tenderness.

\section{Surgical Protocol for skin closure: \\ Surgical site preparation consisted of chlorhexidine vaginally and abdominally unless the}

patient had a contraindication. The skin and subcutaneous tissues were incised using a scalpel or cutting electrocautery. Use of coagulation current on the skin or subcutaneous tissues was not allowed, except focally to attain hemostasis. At the conclusion of surgery, the fascia was closed using two \#1 looped polydioxanone sutures, each anchored in opposite ends of the incision and tied in the middle. After irrigation of the subcutaneous tissues, a $7 \mathrm{~mm}$ Jackson-Pratt drain was placed below Camper's fascia, which in turn was closed with 3-0 plain catgut suture. The skin was closed with staplers. Dressings was retained for at least twentyfour hours. Jackson-Pratt drains were removed just prior to hospital discharge (the drain contains less than $50 \mathrm{ml}$ of serious fluid). Staplers were retained for at least two weeks.

\section{Follow-up:}

The primary outcome results were wound dehiscence, wound infection, wound hematoma and seroma. The secondary outcome results were fever, operation time and amount of blood loss. All patients were seen one or more times in the clinic within eight weeks of surgery for assessment of their surgical wound.

\section{Statistical Analysis}

All data were collected, tabulated and statistically analyzed using SPSS 22.0 for windows. Data were tested for normal distribution using the Shapiro Walk test. Qualitative data were represented as frequencies and relative percentages. Chi square test $\left(\chi^{2}\right)$ and Fisher exact was used to calculate difference between qualitative variables as indicated. Quantitative data were expressed as mean \pm SD (Standard deviation) for parametric and median and range for non-parametric data. Independent $\mathrm{T}$ test and Mann Whitney test were used to calculate difference between quantitative variables in two groups for parametric and nonparametric variables respectively. Regression analysis using the stepwise method was used to determine the potential factors associated with wound complications. All statistical comparisons were two tailed with significance Level of $\mathrm{P}$-value $\leq 0.05$ indicates significant, $\mathrm{p}<0.001$ indicates highly significant difference while, $\mathrm{P}>0.05$ indicates Non-significant difference.

\section{RESULTS}

Table 1: shows that there is no significant differences in demographic data between 2 groups. There was no significant differences between two groups according to body mass index. that uterine cancer was the most prevalent complications. 
Table (1): Demographic data of the studied patients

\begin{tabular}{|c|c|c|c|c|}
\hline \multicolumn{2}{|c|}{ Variable } & $\begin{array}{l}\text { Study group } \\
(\mathrm{n}=43)\end{array}$ & $\begin{array}{l}\text { Control group } \\
\quad(n=43)\end{array}$ & $P$ value \\
\hline \multicolumn{2}{|c|}{$\begin{array}{l}\text { Age (years) } \\
\text { Media }\end{array}$} & $\begin{array}{l}25.29 \pm 3.69 \\
28(30-65)\end{array}$ & $\begin{array}{l}23.26 \pm 3.57 \\
21(30-65)\end{array}$ & .011 \\
\hline \multicolumn{2}{|c|}{$<40$ years } & $10(23.2 \%)$ & $9(20.9 \%)$ & .528 \\
\hline \multicolumn{2}{|c|}{$41-50$ years } & $15(34.8 \%)$ & $11(25.6 \%)$ & \\
\hline \multicolumn{2}{|c|}{$51-60$ years } & $18(41.9 \%)$ & $23(53.5 \%)$ & \\
\hline \multirow{2}{*}{ Residence } & Rural & $23(53.5 \%)$ & $24(55.8 \%)$ & .829 \\
\hline & Urban & $20(46.5 \%)$ & $19(44.2 \%)$ & \\
\hline \multicolumn{5}{|c|}{ Body Mass Index } \\
\hline \multicolumn{2}{|c|}{$\begin{array}{c}\text { Mean } \pm \text { SD } \\
\text { Range }\end{array}$} & $\begin{array}{c}34.34 \pm 2.81 \\
30-39\end{array}$ & $\begin{array}{l}34.34 \pm 2.81 \\
30-39\end{array}$ & 1 \\
\hline \multicolumn{5}{|c|}{ Indications of surgery } \\
\hline \multicolumn{2}{|c|}{ Uterine cancer } & $30(69.8 \%)$ & $26(60.4 \%)$ & .617 \\
\hline \multicolumn{2}{|c|}{ Ovarian cancer } & $9(20.9 \%)$ & $12(27.9 \%)$ & .175 \\
\hline \multicolumn{2}{|c|}{ Cervical cancer } & $4(9.3 \%)$ & $5(11.6 \%)$ & .575 \\
\hline
\end{tabular}

Table 2: shows that there is a significant differences between 2 groups in DM.

Table (2): Past medical History of the studied patients

\begin{tabular}{|c|c|c|c|}
\hline Variable & $\begin{array}{c}\text { Study group } \\
(\mathrm{n}=43)\end{array}$ & $\begin{array}{c}\text { Control group } \\
(\mathrm{n}=43)\end{array}$ & P value \\
\hline Smoking & 0 & $1(2.3 \%)$ & .319 \\
\hline DM & $21(48.8 \%)$ & $16(18.6 \%)$ & .000 \\
\hline HTN & $12(27.9 \%)$ & $18(41.9 \%)$ & .175 \\
\hline
\end{tabular}

Table 3: shows that there is a significant difference between patients of study group and control group regarding wound complications incidence.

Table (3): Wound complication incidence among the studied patients according to using protocol.

\begin{tabular}{|l|c|c|c|}
\hline & $\begin{array}{c}\text { Study group } \\
(\mathrm{n}=43)\end{array}$ & $\begin{array}{c}\text { Control group } \\
(\mathrm{n}=43)\end{array}$ & $\mathbf{P}$ \\
\hline Wound complication & $6(14 \%)$ & $20(46.5 \%)$ & $\mathbf{. 0 0 1}$ \\
\hline
\end{tabular}

Table 4: shows that (100\%) in study group, (80\%) in control group had seroma, (100\%) in study group, (60\%) in control group had wound dehiscence, wound infection and wound hematoma respectively.

Table (4): Type of wound complications in study and control group .

\begin{tabular}{|c|c|c|c|c|c|}
\hline & & $\begin{array}{c}\text { Wound complication } \\
\text { study patients } \\
(\mathrm{n}=6)\end{array}$ & $\begin{array}{l}\text { Wound complication } \\
\text { control Patients } \\
(n=20)\end{array}$ & Test & P value \\
\hline \multirow{3}{*}{ Type } & $\begin{array}{c}\text { Wound } \\
\text { dehiscence }\end{array}$ & $6(100 \%)$ & $12(60 \%)$ & .339 & .1559 \\
\hline & $\begin{array}{c}\text { Wound } \\
\text { infection }\end{array}$ & $2(33.3 \%)$ & $4(20 \%)$ & .753 & .385 \\
\hline & $\begin{array}{c}\text { Wound } \\
\text { hematoma }\end{array}$ & $1(16.7 \%)$ & $1(16.7 \%)$ & - & 1 \\
\hline \multicolumn{2}{|c|}{ Seroma } & $6(100 \%)$ & $14(80 \%)$ & .315 & .575 \\
\hline
\end{tabular}


Table 5: shows that there is a significant difference between the groups regarding operative time.

Table (5): Secondary outcome results of the studied patients.

\begin{tabular}{|c|c|c|c|c|}
\hline Variable & $\begin{array}{c}\text { Study group } \\
(\mathrm{n}=43)\end{array}$ & $\begin{array}{c}\text { Control group } \\
(\mathrm{n}=43)\end{array}$ & Test & P value \\
\hline $\begin{array}{c}\text { Operative time (min) } \\
\text { Mean } \pm \text { SD }\end{array}$ & $126.57 \pm 14.32$ & $156.67 \pm 12.22$ & 10.5 & $.000^{* *}$ \\
\hline $\begin{array}{c}\text { Blood loss (ml) } \\
\text { Mean } \pm \text { SD }\end{array}$ & $211.82 \pm 93.59$ & $201.81 \pm 91.52$ & .501 & .617 \\
\hline Fever & $10(23.2 \%)$ & $15(34.8 \%)$ & .315 & .575 \\
\hline
\end{tabular}

Table 6: shows that BMI, Smoking, DM, longer operative time and massive blood loss were significantly associated with wound complications in study group.

Table (6): Multivariate Logistic regression analysis to determine the associated factors with wound complication in study group.

\begin{tabular}{|c|c|c|c|c|c|}
\hline & \multirow{2}{*}{ OR } & \multirow{2}{*}{ S.E. } & \multirow{2}{*}{ Sig. } & \multicolumn{2}{|c|}{ 95\% C.I. } \\
\cline { 5 - 6 } & & & & \multirow{2}{*}{ Lower } & Upper \\
\hline Age & 1.077 & 0.060 & 0.216 & 0.958 & 1.211 \\
\hline BMI & 2.448 & 0.204 & $\mathbf{0 . 0 0 7}$ & 0.971 & 5.216 \\
\hline Smoking & 0.160 & 0.592 & $\mathbf{0 . 0 1 4}$ & 0.050 & 0.512 \\
\hline DM & 27.894 & 1.327 & $\mathbf{0 . 0 1 2}$ & 2.072 & 75.579 \\
\hline HTN & 0.442 & 0.928 & 0.379 & 0.072 & 2.723 \\
\hline Cancer diagnosis & 2.796 & 1.423 & 0.183 & 3.852 & 7.945 \\
\hline Operative time & 0.942 & 0.026 & $\mathbf{0 . 0 4 2}$ & 0.894 & 0.992 \\
\hline Blood loss & 2.039 & 0.926 & $\mathbf{0 . 0 3 5}$ & 0.546 & 4.253 \\
\hline
\end{tabular}

Table 7: shows that BMI, DM, longer operative time and massive blood loss were significantly associated with wound complications in control group.

Table (7): Multivariate Logistic regression analysis to determine the associated factors with wound complication in control group.

\begin{tabular}{|c|c|c|c|c|c|}
\hline & \multirow{2}{*}{ OR } & \multirow{2}{*}{ S.E. } & \multirow{2}{*}{ Sig. } & \multicolumn{2}{|c|}{ 95\% C.I. } \\
\cline { 5 - 6 } & & & & Lower & Upper \\
\hline Age & .250 & .032 & .083 & .052 & 1.119 \\
\hline BMI & 1.564 & .031 & $\mathbf{. 0 1 8} *$ & .324 & 1.755 \\
\hline Smoking & .659 & .146 & .072 & .078 & 5.190 \\
\hline DM & 1.474 & .045 &. $\mathbf{0 2 5} *$ & 1.034 & 6.592 \\
\hline HTN & 2.106 & .062 & .416 & .350 & 12.679 \\
\hline Cancer diagnosis & .997 & .007 & .932 & .924 & 1.075 \\
\hline Operative time & .891 & .095 & $\mathbf{. 0 1 3} *$ & .765 & 1.037 \\
\hline Blood loss & 2.235 & .067 & $\mathbf{. 0 0 6} *$ & .942 & 7. \\
\hline
\end{tabular}

\section{DISCUSSION}

In the present study Patients' ages ranged 33 to 60 years with mean $48.55 \pm 7.38$ years. The mean BMI was $34.34 \pm 2.81 \mathrm{~kg} / \mathrm{m}^{2}$.

Kuroki et al. ${ }^{(13)}$ found that most women had a BMI between $30-39.9 \mathrm{~kg} / \mathrm{m}^{2}$, although women who received stapler had a lower mean BMI than those closed with suture ( $\left.37.3 \mathrm{vs} 38.9 \mathrm{~kg} / \mathrm{m}^{2}\right)$.

In the current study the most common indications for surgery were uterine cancer $(69.8 \%)$ in study group and $(60.4 \%)$ in control group, ovarian cancer (20.9\%) in the study group and (27.9\%) in Control group and cervical cancer $(9.3 \%)$ in study group and (11.6\%) in Control group. This came in agreement with Mullen et al. ${ }^{(14)}$ who found that the most common indication for surgery was malignancy (58.9\%). and disagreement with Novetsky et al. ${ }^{(15)}$ who found that $33 \%$ of the procedures were done for benign indications.

In the present study, DM was the most finding medical history comprised (48.8\%) in study group and 
(18.6\%) in Control group then hypertension comprised $(27.9 \%)$ in study group and (41.9) in control group and lastly $1.2 \%$ were smokers in Control group. That found 21 patients had diabetes. Kuroki et al. ${ }^{(13)}$ found that the majority of patients were not diabetic, and had a cancer diagnosis.

In the current study, wound complications occurred in $30.2 \%$ of women. Wound complication in study group was $14 \%$ while it was $46.5 \%$ in Control group.

This study states that drain and saline wash is effective for reducing the incidence of wound complications $(\mathbf{p}<0.001)$. This agrees with Allaire $\boldsymbol{e t}$ al. ${ }^{(16)}$ who reported that a subcutaneous drain and saline wash is effective for reducing the incidence of wound complications.

Ghana et al. ${ }^{(17)}$ found that abdominal binders can increase compressing the abdomen post-surgery. Moreover, compression increases blood flow and reduces inflammation at the incision site, both of which are effective in rapid tissue repair this agrees with this study (p 0.001) .

As for the use of subcutaneous drains in gynecology patients, Gallup et al. (18) reported a decrease in the number of wound complications with placement of a drain on retrospective analysis (3\% vs. $42 \%$, pb .0001); however, on randomization in a followup study, a statistically significant difference was not demonstrated and this disagrees with study.

Inotsume-Kojima et al. (19), Boesch et al. ${ }^{(20)}$, Gates et al. (21) stated that there were special considerations when obese patients undergo surgery. Obesity prevents wound healing resulting from the large dead space in the fat layer, increased tension on the wound and steatolysis. The drain serves several purposes: it decreases the dead space in fat layer, adheres to the fat layer and drains serous effusion. Since the first two days are very important, they have never removed a drain within $72 \mathrm{~h}$ postoperatively, even when there is no discharge. However, meta-analyses have shown that the effect of using a subcutaneous drain in obese women undergoing laparotomy remains controversial.

This came in agreement with Kuroki et al. (13) who found that wound complications occurred in $33 \%$ of obese women $14 \%$ in study group and $46.5 \%$ in control group found that $34 \%$ of patients had wound complications.

Kuroki et al. ${ }^{(13)}$ found that wound complications occurred in $33 \%$ of obese women. Novetsky et al. (15) found that $37 \%$ of patients had a wound complication within eight weeks of surgery. In two meta-analyses of randomized controlled trials Clay $\boldsymbol{e t}$ al. ${ }^{(22)}$ and Tuuli $\boldsymbol{e t}$ al. ${ }^{(23)}$ demonstrated a twofold increased risk of wound complications with stapler closure in cesarean sections. Tuuli et al. ${ }^{(23)}$ reported a wound complication rate of 107/803 (13.4\%) with staples.

In disagreement with these studies, an RCT that included more than 200 women undergoing a vertical incision during gynecological surgery has demonstrated that in obese women with $3 \mathrm{~cm}$ of subcutaneous fat, the drain produced no significant change in the rate of wound complications. These studies used a Jacksone Pratt drain (a flat, fully perforated drain; Allegiance Healthcare Corporation, McGaw Park, IL, USA) for the drainage of subcutaneous fat, and stapler for skin closure ${ }^{(24)}$.

In this study we found that abdominal binder reduce wound complications (p 0.001) but Giller, who study the effect of abdominal binders post-surgery had found no effect on post-operative pain, perceived distress, hemoglobin, hematocrit, and extent of painkiller consumption ${ }^{(25)}$.

In the present study, we used polydioxanone suture with less wound infection rate. This came in agreement with Naz et al. (26) who found that polydioxanone suture causes less inflammatory response and has less chances of wound infection.

It has been observed in different studies that low incidence of wound infection is experienced with polydioxanone suture ${ }^{(27)}$.

Polydioxanone has a low affinity for microorganisms. This lower bacterial affinity is believed to be partially due to its mono-filament configuration which has lower surface area than braided structures ${ }^{(\mathbf{2 8})}$.

In the present study there was significant differences between 2 groups regarding to operative time. The mean operative time was $126.57 \pm 14.32$ minutes in study group and 156.67 \pm 12.22 minutes in control group with mean estimated blood loss was $211.82 \pm 93.59 \mathrm{ml}$ in study group and $201.81 \pm 91.52 \mathrm{ml}$ in control group.

Novetsky et al. ${ }^{(15)}$ found that the median duration of surgery was $142 \mathrm{~min}$ and the median estimated blood loss (EBL) was $300 \mathrm{~mL}$.

In the current study, all patients received prophylactic antibiotic. This came in agreement with Novetsky et al. ${ }^{(15)}$ who found that antibiotics were given in $94 \%$ of cases. El-Nashar and colleagues ${ }^{(29)}$ conducted a retrospective cohort study in the use of extended antibiotic prophylaxis for the prevention of surgical site infections in morbidly obese women whose mean BMI was $42.6 \mathrm{~kg} / \mathrm{m} 2$ undergoing a hysterectomy and medically indicated panniculectomy. The patients received intravenous cefazolin $2 \mathrm{~g}$ within $60 \mathrm{~min}$ of incision and ciprofloxacin twice daily for at least 2 weeks while the subcutaneous drains remained in place. They found a reduced number of surgical site infections (5.9 vs. $27.9 \%$; p b 0.001) in the cohort with extended antibiotics.

In the present study, BMI, Smoking, DM, longer operative time and blood loss were significantly associated with wound complications. These came in agreement with Kuroki et al. ${ }^{(13)}$ who found that BMI $(\mathrm{P}<0.001)$, duration of surgery $(\mathrm{P}=0.03)$, maximum postoperative glucose measured as inpatient $(\mathrm{P}=0.02)$ and diabetes $(\mathrm{P}=0.03)$, were significant correlates of wound complication. 
Novetsky et al. ${ }^{(15)}$ found that BMI $\geq 40 \mathrm{~kg} / \mathrm{m}^{2}$, ASA class $\geq 3$ and subcutaneous depth $\geq 4 \mathrm{~cm}$ were all associated with a higher risk of wound complication. Longer duration of surgery, inappropriate dosing of antibiotics prior to incision, EBL N500 mL, history of prior surgery, prior tobacco use, diabetes mellitus and surgery for a cancer diagnosis were not associated with a higher risk of wound complication.

Kuroki et al. ${ }^{(13)}$ found that BMI, duration of surgery, maximum postoperative glucose measured as inpatient, diabetes, and prior abdominal surgery were significant correlates of wound complication. However, risk factors that remained in the final model after multivariate stepwise selection were BMI, maximum postoperative glucose, prior abdominal surgery, tobacco use, as well as the two factors that were forced to stay in every model during the selection process, skin closure type and subcutaneous drain placement.

The institutional study showed that obesity is a risk factor for overall and postoperative surgical complications, including wound complications. They found a higher incidence of wound and infectious complications among obese women with cancer surgery. In addition, they showed that the total number of complications increased with BMI, identifying morbidly obese at a particularly high risk ${ }^{(30,31)}$.

In this study, seroma was present $100 \%$ in study group and $80 \%$ in control group, fever is $23.2 \%$ in study group and $34.8 \%$ in control group, wound dehiscence in $100 \%$ in study group and $60 \%$ in control group and wound infection in $33.3 \%$ in study group and \% in control group.

The wound infection can be due type of surgery, diabetes mellitus, poor technique and immune disorders, obesity may also lead to this complication. If subcutaneous potential space is left during wound closure or the drain is not placed, seroma may form Ho et al. ${ }^{(32)}$. The obese patients are more prone to develop seroma and wound infection despite all the precautions (33).

Fat acts as pile deriver and the tensile strength of surgical wound is less in obesity. Difficulty during abdominal wound closure may also contribute towards early and late complications. Despite proper surgical technique, wound dehiscence and incisional hernia may occur ${ }^{(34)}$.

The study by Hourigan ${ }^{(35)}$ has shown that there has been increased recognition of the obesity regarding its contribution to worse outcomes in surgical patients. In particular, it has been up to $50 \%$ increased risk of wound infection among the obese patients undergoing abdominal surgery. This is more than our study and is because of the reason that they included patients with all types of the wounds.

\section{CONCLUSIONS}

It could be concluded that using this specific protocol (saline wash, suture material (Polydioxanone suture), subcutaneous drain and binder) may decrease the incidence of wound complications in obese women undergoing a gynecologic procedure via a vertical abdominal incision.

We recommend optimizing operative techniques and protocols to reduce wound infection. These are essential to improve perioperative outcomes and should be supplemented with management of modifiable risk factors such as obesity, diabetes, and other contributing comorbidities.

\section{REFERENCES}

1. Poelemeijer Y, Lijftogt N, Detering $R$ et al. (2018): Obesity as a determinant of perioperative and postoperative outcome in patients following colorectal cancer surgery: A population-based study (2009-2016): European Journal of Surgical Oncology, 44(12): 18491857.

2. Adams K, Leitzmann M, Ballard-Barbash $\mathbf{R}$ et al. (2014): Body mass and weight change in adults in relation to mortality risk. American Journal of Epidemiology, 15179 (2): 135-44.

3. Arroyo K, Herron D (2013): The epidemiology of obesity. InBariatric Endoscopy. Springer New York., Pp. 1-9. https://www. researchgate. net/publication/278662168_The_Epidemiology_of_Obe sity

4. Shuster A, Patlas M, Pinthus J et al. (2014): The clinical importance of visceral adiposity: a critical review of methods for visceral adipose tissue analysis. The British Journal of Radiology, 16(4): 143-151.

5. Nelson G, Bakkum-Gamez J, Kalogera $\mathrm{E}$ et al. (2019): Guidelines for perioperative care in gynecologic/oncology: Enhanced Recovery After Surgery (ERAS) Society recommendations-2019 update. International Journal of Gynecologic Cancer, 29(4): 651-668.

6. Tuveri M, Tuveri A, Nicolo E et al. (2015): Incisional Hernia--" Difficult case" as specialistic case: real loss of substance, multi recurrences, infections, fistulas, lombocel, burst abdomen, reconstruction of the entire wall. Hernia, 119: 225-29.

7. Taylor A, DeBoard Z, Gauvin J (2015): Prevention of postoperative pulmonary complications. Surgical Clinics of North America, 3095 (2): 237-54.

8. Falagas M, Barefoot L, Griffith L (1996): Risk factors leading to clinical failure in the treatment of intraabdominal or skin/soft tissue infections. Eur J Clin Microbiol Infect Dis., 15: 913-921.

9. Aho J, Nickerson T, Thiels C et al. (2016): Prevention of postoperative seromas with dead space obliteration: a case-control study. International Journal of Surgery, 29: 70-73.

10. Sandy-Hodgetts K, Carville K, Leslie G (2015): Determining risk factors for surgical wound dehiscence: a literature review. International Wound Journal, 112 (3): 265-75.

11. De Hert S, Staender S, Fritsch G et al. (2018): Preoperative evaluation of adults undergoing elective noncardiac surgery. European Journal of Anaesthesiology, 35(6): 407-465.

12. Banerjee A, Selzer D (2016): Optimizing Perioperative Management: Perioperative Care and Protocols to Prevent and Detect Early Complications. In Bariatric Surgery Complications and Emergencies. Springer 
International Publishing. Pp. 31-49. https://www.researchgate.net/publication/ 303521581_Optimizing_perioperative_management_Pe rioperative_care_protocols_to_prevent_detect_early_co mplications

13. Kuroki L, Mullen M, Massad L et al. (2017): Wound complication rates after staples or suture for midline vertical skin closure in obese women: a randomized controlled trial. Obstetrics and Gynecology, 130(1): 9196.

14. Mullen M, Porcelli B, Cripe J et al. (2020): Modified frailty index is predictive of wound complications in obese patients undergoing gynecologic surgery via a midline vertical incision. Gynecologic Oncology, 157(1): 287-292.

15. Novetsky A, Zighelboim I, Guntupalli S et al. (2014): A phase II trial of a surgical protocol to decrease the incidence of wound complications in obese gynecologic oncology patients. Gynecologic Oncology, 134(2): 233237.

16. Allaire A, Fisch J, McMahon M (2000): Subcutaneous drain vs. suture in obese women undergoing cesarean delivery. A prospective, randomized trial. J Reprod Med., 45:327-331.

17. Ghana S, Hakimi S, Mirghafourvand M et al. (2017): The effects of abdominal binder on wound healing and consumed pain medications after cesarean section: A randomized control trial. Iranian Red Crescent Medical Journal, 19(4): 1-8.

18. Gallup D, Gallup D, Nolan T et al. (1996): Use of a subcutaneous closed drainage system and antibiotics in obese gynecologic patients. Am J Obstet Gynecol., 175:358-361.

19. Inotsume-Kojima Y, Uchida T, Abe M et al. (2011): A combination of subcuticular sutures and a drain for skin closure reduces wound complications in obese women undergoing surgery using vertical incisions. Journal of Hospital Infection, 77(2): 162-165.

20. Boesch C, Umek W (2009): Effects of wound closure on wound healing in gynecologic surgery: a systematic literature review. J Reprod Med., 54: 139-144.

21. Gates S, Anderson E (2005): Wound drainage for caesarean section. Cochrane Database Syst Rev., 454953.

22. Clay F, Walsh C, Walsh S (2011): Staples vs subcuticular sutures for skin closure at cesarean delivery: a meta-analysis of randomized controlled trials. Am J Obstet Gynecol., 204(5): 378-383.
23. Tuuli M, Rampersad R, Carbone J et al. (2011): Staples compared with subcuticular suture for skin closure after cesarean delivery: a systematic review and meta-analysis. Obstet Gynecol., 117(3):682-690.

24. Cardosi R, Drake J, Holmes $\mathrm{S}$ et al. (2006): Subcutaneous management of vertical incisions with 3 or more centimeters of subcutaneous fat. Am J Obstet Gynecol., 195:607-614.

25. Havey R, Herriman E, O'Brien D (2013): Guarding the gut: early mobility after abdominal surgery. Crit Care Nurs Q., 36(1):63-72.

26. Naz S, Memon S, Jamali $M$ et al. (2017): Polydioxanone versus polypropylene closure for midline abdominal incisions. Journal of Ayub Medical College Abbottabad, 29(4): 591-594.

27. Weiland D, Bay R, Del Sordi S (1998): Choosing the best abdominal closure by meta-analysis. Am J Surg., 176(6):666-70.

28. Wang Z, Pu L, Li G et al. (1994): Polydioxanone absorbable sutures in vascular anastomoses: experimental and preliminary clinical studies. Cardiovascular Surgery, 2(4): 508-513.

29. El-Nashar S, Diel C, Swanson C et al. (2010): Extended antibiotic prophylaxis for prevention of surgical site infections in morbidly obese women who undergo combined hysterectomy and medically indicated panniculectomy: a cohort study. AJOG., 202: 1-9.

30. Mahdi H, Jernigan A, Aljebori Q et al. (2015): The impact of obesity on the 30-day morbidity and mortality after surgery for endometrial cancer. Journal of Minimally Invasive Gynecology, 22(1): 94-102.

31. Pavelka J, Ben-Shachar I, Fowler J et al. (2004): Morbid obesity and endometrial cancer: surgical, clinical, and pathologic outcomes in surgically managed patients. Gynecologic Oncology, 95(3): 588-592.

32. Ho V, Eachempati S, Barie P (2013): Surgical Site Infections 11. Common Problems in Acute Care Surgery, 12: $139-143$.

33. Gusenoff J (2014): Prevention and Management of Complications in Body Contouring Surgery. Clinics in Plastic Surgery, 3141 (4): 805-18.

34. Krpata D, Blatnik J, Novitsky Y et al. (2013): Evaluation of high-risk, comorbid patients undergoing open ventral hernia repair with synthetic mesh. Surgery, 31153(1): 120-125.

35. Hourigan $\mathbf{J}$ (2011): Impact of obesity on surgical site infection in colon and rectal surgery. Clinics in Colon and Rectal Surgery, 24 (04): 283-90. 